\title{
REVIEW
}

Open Access

\section{Comparison of effect between nasobiliary drainage and biliary stenting in malignant biliary obstruction: a systematic review and updated meta-analysis}

Wei Zhang ${ }^{1}$ and $\mathrm{Xu}$ Che $\mathrm{e}^{1,2^{*}}$

\begin{abstract}
Background: To compare the efficacy of endoscopic nasobiliary drainage (ENBD) and endoscopic biliary stenting (EBS) in preoperative biliary drainage (PBD).

Methods: ENBD and EBS related literature of patients with malignant biliary obstruction published before September 2019 were collected from PubMed, EMBASE, and Cochrane Library for comparison analysis. Revman 5.3 statistical software was used for analysis.

Results: Nine studies were used for our comparative study. A total of 1435 patients were included, which consisted of 813 in the ENBD group and 622 in the EBS group. Meta-analysis showed that patients with malignant biliary obstruction who received ENBD had reductions in the rates of preoperative cholangitis ( $R R=0.46,95 \% \mathrm{Cl}=0.34$ $0.62, P<0.00001)$, preoperative pancreatitis $(R R=0.69,95 \% \mathrm{Cl}=0.50-0.95, P=0.02)$, stent dysfunction $(\mathrm{RR}=$ $0.58,95 \% \mathrm{Cl}=0.43-0.80, P=0.0008)$, morbidity $(\mathrm{RR}=0.77,95 \% \mathrm{Cl}=0.64-0.93, P=0.007)$, and postoperative pancreatic fistula $(R R=0.65,95 \% \mathrm{Cl}=0.45-0.92, P=0.02$ ) compared with patients who received EBS.

Conclusions: The rates of preoperative cholangitis, preoperative pancreatitis, post-operative pancreatic fistula, stent dysfunction, and morbidity of ENBD patients were lower than those of EBS patients. In clinical practice, the physical condition of each patient and their tolerance should be fully considered. ENBD should be given priority. EBS should be replaced if stent dysfunction or intolerance occurs.
\end{abstract}

Keywords: Endoscopic biliary stenting, Endoscopic nasobiliary drainage, Malignant biliary obstruction, Preoperative biliary drainage

\footnotetext{
* Correspondence: yixuetg@foxmail.com

'Department of Pancreatic and Gastric Surgery, National Cancer Center/ National Clinical Research Center for Cancer/Cancer Hospital, Chinese Academy of Medical Sciences and Peking Union Medical College, 17 Panjiayuan Nanli, Chaoyang District, Beijing 100021, China

${ }^{2}$ Department of Hepatobiliary and Pancreatic Surgery, National Cancer Center/National Clinical Research Center for Cancer/Cancer Hospital \& Shenzhen Hospital, Chinese Academy of Medical Sciences and Peking Union Medical College, Shenzhen 518116, China
}

(c) The Author(s). 2020 Open Access This article is licensed under a Creative Commons Attribution 4.0 International License, which permits use, sharing, adaptation, distribution and reproduction in any medium or format, as long as you give appropriate credit to the original author(s) and the source, provide a link to the Creative Commons licence, and indicate if changes were made. The images or other third party material in this article are included in the article's Creative Commons licence, unless indicated otherwise in a credit line to the material. If material is not included in the article's Creative Commons licence and your intended use is not permitted by statutory regulation or exceeds the permitted use, you will need to obtain permission directly from the copyright holder. To view a copy of this licence, visit http://creativecommons.org/licenses/by/4.0/ The Creative Commons Public Domain Dedication waiver (http://creativecommons.org/publicdomain/zero/1.0/) applies to the data made available in this article, unless otherwise stated in a credit line to the data. 


\section{Introduction}

Malignant biliary obstruction (MBO) is a large group of malignant tumors that cause biliary obstruction, including hilar cholangiocarcinoma, pancreatic head cancer, and cholangiocarcinoma. Surgical radical resection is the only treatment that could cure and obtain a long-term survival rate, and the majority of patients need combined hepatectomy to achieve a radical cure [1]. Most patients with $\mathrm{MBO}$ diseases have obstructive jaundice of varying degrees. Preoperative biliary drainage (PBD) is needed to improve liver function, coagulation function, nutritional status, and immune function in order to avoid acute cholangitis and promote liver regeneration, as well as reducing the risk of operative and postoperative complications [2-4]. Common PBD methods include endoscopic biliary stent (EBS), endoscopic nasobiliary drainage (ENBD), and percutaneous transhepatic biliary drainage (PTBD). Each PBD has a certain risk of complications which can endanger life and result in a lost opportunity for an operation. It has been reported that PBD can cause complications such as biliary hemorrhage, acute cholangitis, and acute pancreatitis, with an incidence of $8 \%$. In addition, PBD can also cause bacterial contamination of bile, and therefore increases the probability of infection after an operation, and even metastasis of tumors [5-7]. PTBD belongs to invasive drainage, which can be placed with multiple drainage tubes to relieve jaundice. However, PTBD is not considered as the first choice due to its increased probability of tumor metastasis by the invasive procedure. For an easy-to-operate drainage EBS and ENBD, it is still not clear which one has the best preoperative effect to reduce jaundice. Multicenter large sample randomized controlled clinical trials are still needed. Therefore, we systematically reviewed relevant studies since the emergence of EBS and ENBD, and made a quantitative analysis to explore their implementation effect, application value, and mode selection in order to provide an evidence-based reference for clinical practice.

\section{Methods}

\section{Retrieval strategy}

The literature was retrieved from PubMed, EMBASE, and Cochrane Library databases using the keywords "nasobiliary drainage," "nasobiliary catheter," "nasobiliary drain," and "ENBD," and the combination of "internal endoscopic biliary drainage," "internal EBD," "endoscopic biliary stenting," "EBS," "endoscopic retrograde biliary drainage," "ERBD," "stent," and "stenting" in order to identify relevant studies published before September 2019. Figure 1 summarizes the process for retrieving relevant literature, and Table 1 summarizes the patient characteristics and surgical results included in the study.

\section{Inclusion criteria}

Inclusion criteria were as follows: (1) study subjects: the cases with confirmed MBO, feasible limited operation; (2) original published literature which contained comparison research on the efficacy of ENBD and EBS, including randomized controlled studies, prospective observational studies, or retrospective observational studies; (3) the sample size of the study: unlimited; (4) follow-up time: more than 3 months; (5) the language of published literature: English; (6) research type: human studies; (7) research indicators: incidence rates of preoperative cholangitis, preoperative pancreatitis, stent dysfunction, morbidity, and postoperative pancreatic fistula.

\section{Data exclusion and quality assessment}

Articles that conformed to the following rules were removed: (1) studies with incomplete information, inability to extract valid data, unresponsive contact with authors, repeated publication, unpublished follow-up, and unknown follow-up time; (2) one-arm study of ENBD or EBS, studies reporting outcomes about ENBD or EBS alone without comparison; (3) $\mathrm{MBO}$ cases that lost the opportunity of surgical treatment; (4) literature written in languages other than English; (5) robotic research, reviews, case reports, and animal experiments.

This meta-analysis only enrolled 9 cohort studies (CSs). CSs were graded according to the NewcastleOttawa Scale (NOS), including selection, comparability, exposure evaluation, or outcome evaluation. NOS adopted the semi-quantitative principle of star system to evaluate the quality of literature, which is divided into 9 stars (Additional file 1 Appendix file 2).

\section{Statistical analysis}

Meta-analysis was performed by Review Manager 5.3 software. Risk ratio (RR) was selected for dichotomous data. Weighted mean difference (WMD) and its 95\% confidence interval (CI) were selected for continuous data. Chi-square test was used for the homogeneity test of each study. The fixed effect model was used only if homogeneity was accepted $\left(I^{2}<35 \%, P<0.05\right)$. If there was significant clinical heterogeneity among the studies, the random effect model was used. $P$ values $<0.05$ were considered as statistically significant. Sensitivity analysis was performed by removing 1 study at a time to assess whether the results could have been markedly affected by a single study. Subgroup analysis was performed according to the factors affecting the outcome. The funnel plots were qualitatively used to judge whether there was publication bias in these studies. Begg's test and Egger's test were quantitatively used to evaluate the publication bias of the included study, as shown in Table 2. The significance level was limited to 0.05 . 


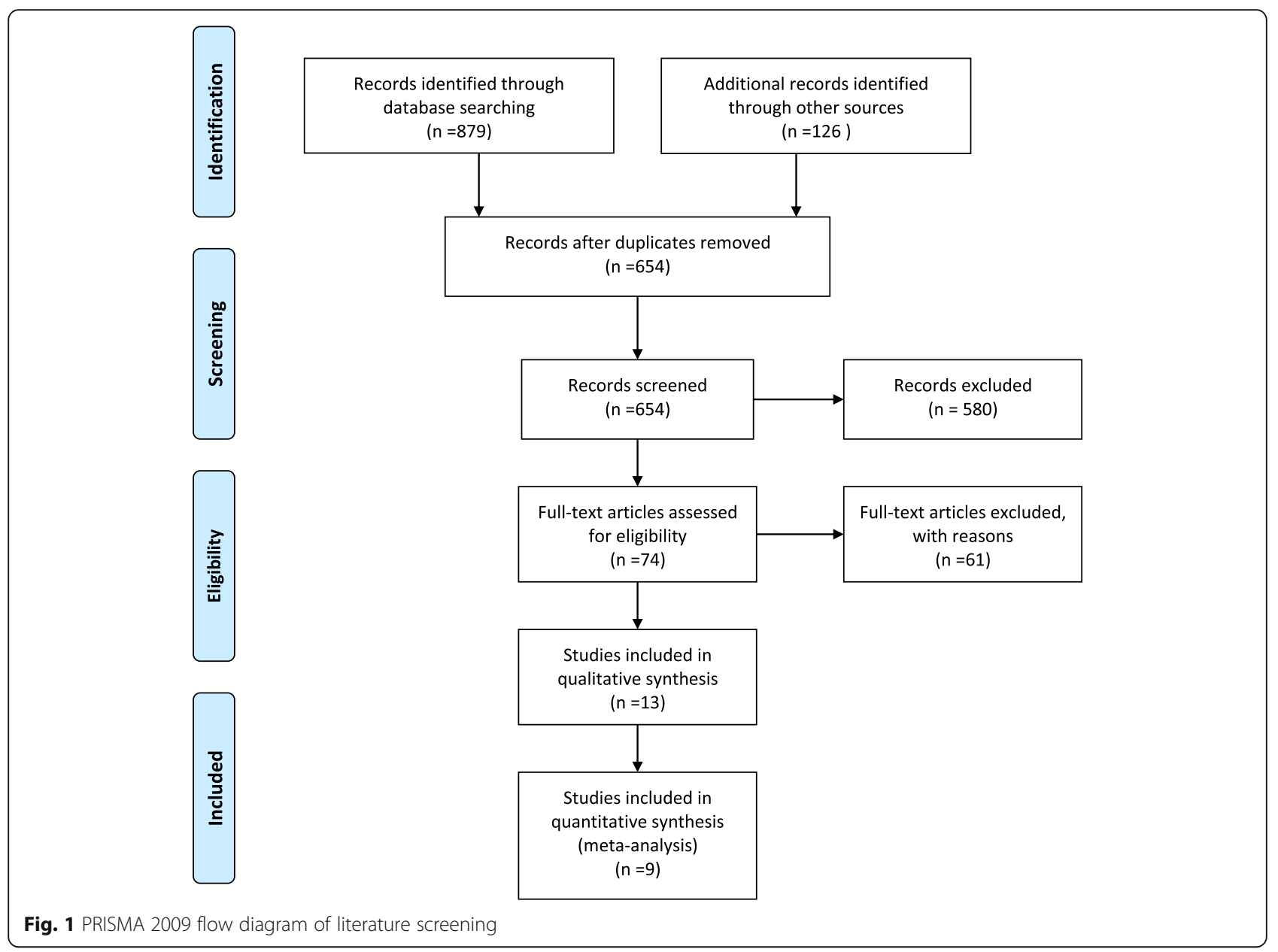

\section{Results}

\section{Search results and study characteristics}

Nine relevant publications were used in this study, 8 RCSs and 1 prospective cohort study. The cumulative sample size in these studies was 1435 patients, including 813 samples in the ENBD group and 622 samples in the EBS group. Basic characteristics and quality assessment of the enrolled documents are shown in Table 1. Metaanalysis results of endpoints from all available studies are shown in Table 2 at end of article.

\section{Incidence of preoperative cholangitis}

From the 9 studies, 813 cases in the ENBD group and 622 cases in the EBS group were used in this metaanalysis [8-16]. Low heterogeneity $\left(I^{2}=19 \%, P=0.27\right)$ was found, so we chose a random-effect model to pool the RR. Overall, the pooled data demonstrated that ENBD was associated with a low incidence of preoperative cholangitis $(\mathrm{RR}=0.46,95 \% \mathrm{CI}=0.34-0.62, P<$ $0.00001)$ in the $\mathrm{MBO}$ patients. Subgroup analysis showed a higher incidence of preoperative cholangitis in the EBS group than in the ENBD group among hilar cholangiocarcinoma $(\mathrm{HCC})$ patients $(\mathrm{RR}=0.50,95 \% \mathrm{CI}=0.19$
1.30, $P=0.16)$ and malignant distal biliary obstruction patients $(\mathrm{RR}=0.38,95 \% \mathrm{CI}=0.26-0.57, P<0.00001)$ (Fig. 2 Additional file 1 Appendix file 4).

\section{Incidence of preoperative pancreatitis}

From 7 studies, 750 cases in the ENBD group and 508 cases in the EBS group were used in this meta-analysis $[8,9,11-16]$. No heterogeneity $\left(I^{2}=0 \%, P=0.93\right)$ was found, so we chose a fixed-effect model to pool the RR. Overall, the pooled data demonstrated that ENBD was associated with a low incidence of preoperative pancreatitis $(\mathrm{RR}=0.69,95 \% \mathrm{CI}=0.50-0.95, P=0.02)$ in the $\mathrm{MBO}$ patients. Subgroup analysis showed there was no significant difference in the preoperative pancreatitis rate between ENBD and EBS in HCC patients $(\mathrm{RR}=0.67$, 95\% CI $=0.30-1.47, P=0.31)$ or malignant distal biliary obstruction patients $(\mathrm{RR}=0.74,95 \% \mathrm{CI}=0.50$ 1.12, $P=0.15$ ) (Fig. 3 Additional file 1 Appendix file 5).

\section{Stent dysfunction rate}

From 6 studies, 464 cases in the ENBD group and 437 cases in the EBS group reported a stent dysfunction rate $[10-16]$. Moderate heterogeneity $\left(I^{2}=39 \%, P=0.15\right)$ 
Table 1 Basic characteristics and quality assessment of enrolled documents

\begin{tabular}{|c|c|c|c|c|c|c|c|c|}
\hline & Country & Study design & Period of study & Type of PBD & Case & $\operatorname{Sex}(M / F)$ & Age & Quality (NOS) \\
\hline \multirow[t]{2}{*}{ Fujii T [8] } & Japan & PC & 2008-2014 & ENBD & 50 & $30 / 20$ & 66.5 (39-83) & 7 \\
\hline & & & & EBS & 72 & $46 / 26$ & $67(38-84)$ & \\
\hline \multirow[t]{2}{*}{ Huang X [9] } & China & $\mathrm{RC}$ & $2005-2014$ & ENBD & 18 & $5 / 13$ & $60.6 \pm 8.4$ & 7 \\
\hline & & & & EBS & 37 & $10 / 27$ & $58.1 \pm 8.3$ & \\
\hline \multirow[t]{2}{*}{ Jo JH [10] } & Korea & $\mathrm{RC}$ & 2005-2012 & ENBD & 13 & $8 / 13$ & $58.9(42-77)$ & 5 \\
\hline & & & & EBS & 42 & 23/19 & $61.1(29-80)$ & \\
\hline \multirow[t]{2}{*}{ Kawakami [11] } & Japan & $\mathrm{RC}$ & 1999-2009 & ENBD & 60 & $44 / 16$ & $71(45-81)$ & 7 \\
\hline & & & & EBS & 20 & $4 / 16$ & $70(59-77)$ & \\
\hline \multirow[t]{2}{*}{ Kawakubo [12] } & Japan & $\mathrm{RC}$ & 2009-2014 & ENBD & 85 & $74 / 44$ & $69 \pm 9$ & 6 \\
\hline & & & & EBS & 33 & & & \\
\hline \multirow[t]{2}{*}{ Nakai Y [13] } & Japan & $\mathrm{RC}$ & 2010-2014 & ENBD & 281 & $189 / 92$ & 71 (64-76) & 7 \\
\hline & & & & EBS & 76 & $47 / 29$ & $70(65-74)$ & \\
\hline \multirow[t]{2}{*}{ Sasahira [14] } & Japan & $\mathrm{RC}$ & 2010-2012 & ENBD & 166 & $64 / 102$ & $70(63-76)$ & 7 \\
\hline & & & & EBS & 253 & $64 / 189$ & $69(62-75)$ & \\
\hline \multirow[t]{2}{*}{ Sugiyama [15] } & Japan & $\mathrm{RC}$ & $2008-2012$ & ENBD & 38 & & & 6 \\
\hline & & & & EBS & 38 & & & \\
\hline \multirow[t]{2}{*}{ Zhang G [16] } & China & $\mathrm{RC}$ & 2009-2016 & ENBD & 102 & $58 / 44$ & $55.26 \pm 9.07$ & 7 \\
\hline & & & & EBS & 51 & $29 / 22$ & $56.24 \pm 9.65$ & \\
\hline
\end{tabular}

EBS endoscopic biliary stenting, ENBD endoscopic nasobililary drainage, NA not available, NOS Newcastle-Ottawa Score, $R C$ retrospective clinical study, $P C$ prospective clinical study

was found, so we chose a random-effect model to pool the RR. Overall, the pooled data demonstrated that ENBD was associated with a low incidence of stent dysfunction $(\mathrm{RR}=0.58,95 \% \mathrm{CI}=0.43-0.80, P=0.0008)$ in $\mathrm{MBO}$ patients. Subgroup analysis showed that the stent dysfunction rate was also higher in the EBS group than in the ENBD group among HCC patients $(\mathrm{RR}=$ 0.0.48, 95\% CI $=0.35-0.67, P<0.0001$ ) and malignant distal biliary obstruction patients $(\mathrm{RR}=0.59,95 \% \mathrm{CI}=$ 0.39-0.90, $P=0.02$ ) (Fig. 4 Additional file 1 Appendix file 6).

\section{Morbidity}

Five studies were used to assess morbidity, which was defined as the incidence of all pre- and postoperative complications [9-11, 14-16]. Although only 1 study

Table 2 Meta-analysis results of all available studies in measured outcomes

\begin{tabular}{|c|c|c|c|c|c|c|c|c|c|c|c|c|}
\hline \multirow[t]{2}{*}{ Measured outcomes } & \multirow[t]{2}{*}{ Subgroup } & \multirow[t]{2}{*}{ No. studies } & \multirow[t]{2}{*}{ No. patients } & \multicolumn{2}{|c|}{$\begin{array}{l}\text { Heterogeneity } \\
\text { test }\end{array}$} & \multirow[t]{2}{*}{ Model } & \multirow[t]{2}{*}{ RR/WMD } & \multirow[t]{2}{*}{$95 \% \mathrm{Cl}$} & \multirow[t]{2}{*}{$P$} & \multicolumn{2}{|l|}{ Begg's test } & \multirow{2}{*}{$\begin{array}{l}\text { Egger's test } \\
P>|t|^{*}\end{array}$} \\
\hline & & & & $\overline{P^{2}(\%)}$ & $P$ & & & & & $\operatorname{Pr}>|z|^{*}$ & $\operatorname{Pr}>|z|^{* *}$ & \\
\hline \multirow[t]{3}{*}{ Preoperative cholangitis } & Total & 9 & 813 vs. 622 & 19.1 & 0.273 & Random & 0.46 & $0.34,0.62$ & $<0.001$ & 0.404 & 0.466 & 0.73 \\
\hline & $\mathrm{HCC}$ & 2 & 145 vs. 53 & 81.5 & 0.02 & Random & 0.5 & $0.19,1.3$ & 0.156 & -- & -- & -- \\
\hline & $\mathrm{DBO}$ & 4 & 535 vs. 439 & 17.4 & 0.259 & Random & 0.38 & $0.26,0.57$ & $<0.001$ & 0.174 & 0.308 & 0.282 \\
\hline \multirow[t]{3}{*}{ Preoperative pancreatitis } & Total & 7 & 750 vs. 508 & 0 & 0.929 & Fixed & 0.69 & $0.50,0.95$ & 0.023 & 0.881 & 1 & 0.551 \\
\hline & $\mathrm{HCC}$ & 2 & 145 vs. 53 & 0 & 0.999 & Fixed & 0.67 & $0.30,1.47$ & 0.314 & -- & -- & -- \\
\hline & $\mathrm{DBO}$ & 3 & 485 vs. 367 & 0 & 0.825 & Fixed & 0.74 & $0.50,1.12$ & 0.152 & 0.602 & 1 & 0.603 \\
\hline \multirow[t]{3}{*}{ Stent dysfunction rate } & Total & 6 & 464 vs. 437 & 38.6 & 0.149 & Random & 0.58 & $0.43,0.8$ & 0.001 & 0.188 & 0.26 & 0.311 \\
\hline & $\mathrm{HCC}$ & 2 & 145 vs. 53 & 0 & 0.319 & Random & 0.48 & $0.35,0.67$ & $<0.001$ & -- & -- & -- \\
\hline & DBO & 2 & 204 vs. 291 & 26.3 & 0.244 & Random & 0.59 & $0.39,0.90$ & 0.015 & -- & -- & -- \\
\hline Morbidity & Total & 5 & 231 vs. 188 & 0 & 0.418 & Fixed & 0.77 & $0.64,0.93$ & 0.007 & 0.142 & 0.221 & 0.163 \\
\hline POPF & Total & 3 & 170 vs. 160 & 7.7 & 0.338 & Fixed & 0.65 & $0.45,0.92$ & 0.016 & 0.602 & 1 & 0.536 \\
\hline
\end{tabular}

HCC hilar cholangiocarcinoma; DBO distant biliary obstruction; POPF postoperative pancreatic fistula; No.number of; RR risk ratio; WMD weighted mean difference; $\mathrm{Cl}$ confidence interval

* $P$ value

**P value (continuity corrected)

--Not applicable 


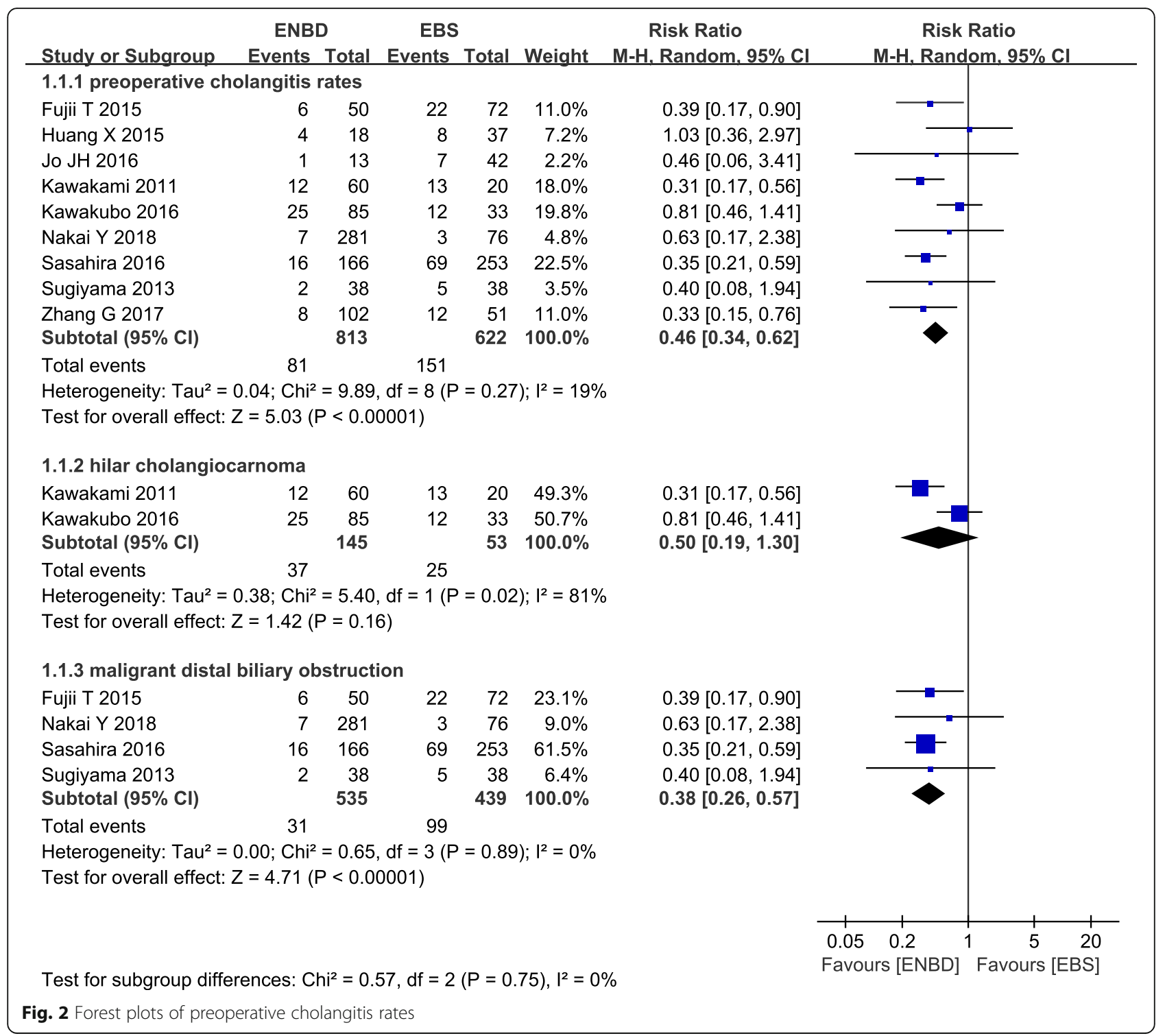

showed that ENBD had a significant advantage in terms of morbidity compared with EBS, the pooled results had no heterogeneity $\left(I^{2}=0 \%, P=0.42\right)$ and showed that ENBD had a significantly lower incidence of morbidity than EBS (RR = 0.77, 95\% CI = 0.64-0.93, $P=0.007$ ) (Fig. 5a Additional file 1 Appendix file 7).

\section{Postoperative pancreatic fistula}

Three studies were used to assess the rate of postoperative pancreatic fistula (POPF) $[8,9,16]$. The pancreatic fistula rate was significantly lower in the ENBD group than in the EBS group $(\mathrm{RR}=0.65,95 \% \mathrm{CI}=0.45-0.92, P=$ $0.02)$ based on the pooled data, which showed low heterogeneity $\left(I^{2}=8 \%, P=0.34\right.$ ) (Fig. $5 \mathrm{~b}$ Additional file 1 Appendix file 8).
Sensitivity analysis and assessment of risk of bias

Sensitivity analysis suggested that the majority data in this meta-analysis were relatively stable. The funnel plots were used to judge whether there was publication bias in these studies. As shown in the funnel plots, the studies are basically symmetrical and the possibility of publication bias is low. No publication bias was detected by Begg's test and Egger's test. (Fig. 6 Additional file 1 Appendix file 9)

\section{Discussion}

Malignant obstruction of the hepatobiliary system is caused by obstruction or compression of bile duct epithelial cancer, gallbladder cancer, pancreatic cancer, or metastatic cancer. The main clinical manifestations are jaundice, abdominal pain, and fever. A large amount of bile retention may cause liver dysfunction, and cause 


\begin{tabular}{|c|c|c|c|c|c|c|c|c|}
\hline Study or Subgroup & $\begin{array}{l}\text { ENBD } \\
\text { Events } \\
\end{array}$ & Total & $\begin{array}{l}\text { EBS } \\
\text { Events }\end{array}$ & Total & Weight & $\begin{array}{l}\text { Risk Ratio } \\
\text { M-H, Fixed, 95\% Cl }\end{array}$ & \multicolumn{2}{|c|}{$\begin{array}{c}\text { Risk Ratio } \\
\text { M-H, Fixed, 95\% Cl }\end{array}$} \\
\hline \multicolumn{9}{|c|}{ 1.2.1 Incidence of preoperative pancreatitis } \\
\hline Zhang G 2017 & 12 & 102 & 12 & 51 & $21.6 \%$ & $0.50[0.24,1.03]$ & & \\
\hline Sugiyama 2013 & 0 & 38 & 1 & 38 & $2.0 \%$ & $0.33[0.01,7.93]$ & & \\
\hline Sasahira 2016 & 14 & 166 & 26 & 253 & $27.9 \%$ & $0.82[0.44,1.52]$ & & \\
\hline Nakai Y 2018 & 39 & 281 & 15 & 76 & $31.9 \%$ & $0.70[0.41,1.21]$ & & \\
\hline Kawakubo 2016 & 12 & 85 & 7 & 33 & $13.6 \%$ & $0.67[0.29,1.54]$ & - & \\
\hline Kawakami 2011 & 2 & 60 & 1 & 20 & $2.0 \%$ & $0.67[0.06,6.97]$ & & \\
\hline Huang X 2015 & 1 & 18 & 1 & 37 & $0.9 \%$ & $2.06[0.14,31.02]$ & & \\
\hline Subtotal $(95 \% \mathrm{Cl})$ & & 750 & & 508 & $100.0 \%$ & $0.69[0.50,0.95]$ & & \\
\hline Total events & 80 & & 63 & & & & & \\
\hline \multicolumn{9}{|c|}{ Heterogeneity: $C h i^{2}=1.89, d f=6(P=0.93) ;\left.\right|^{2}=0 \%$} \\
\hline \multicolumn{9}{|c|}{ Test for overall effect: $Z=2.27(P=0.02)$} \\
\hline \multicolumn{9}{|c|}{ 1.2.2 hilar cholangiocarcinoma } \\
\hline Kawakubo 2016 & 12 & 85 & 7 & 33 & $87.1 \%$ & $0.67[0.29,1.54]$ & & \\
\hline Kawakami 2011 & 2 & 60 & 1 & 20 & $12.9 \%$ & $0.67[0.06,6.97]$ & & \\
\hline Subtotal $(95 \% \mathrm{Cl})$ & & 145 & & 53 & $100.0 \%$ & $0.67[0.30,1.47]$ & & \\
\hline Total events & 14 & & 8 & & & & & \\
\hline \multicolumn{9}{|c|}{ Heterogeneity: $\mathrm{Chi}^{2}=0.00, \mathrm{df}=1(P=1.00) ; \mathrm{I}^{2}=0 \%$} \\
\hline \multicolumn{9}{|c|}{ Test for overall effect: $Z=1.01(P=0.31)$} \\
\hline \multicolumn{9}{|c|}{ 1.2.3 malignant distal biliary obstruction } \\
\hline Sugiyama 2013 & 0 & 38 & 1 & 38 & $3.3 \%$ & $0.33[0.01,7.93]$ & & \\
\hline Sasahira 2016 & 14 & 166 & 26 & 253 & $45.1 \%$ & $0.82[0.44,1.52]$ & & \\
\hline Nakai Y 2018 & 39 & 281 & 15 & 76 & $51.7 \%$ & $0.70[0.41,1.21]$ & & \\
\hline Subtotal $(95 \% \mathrm{Cl})$ & & 485 & & 367 & $100.0 \%$ & $0.74[0.50,1.12]$ & & \\
\hline Total events & 53 & & 42 & & & & & \\
\hline \multicolumn{9}{|c|}{ Heterogeneity: $\mathrm{Chi}^{2}=0.38, \mathrm{df}=2(P=0.82) ; \mathrm{I}^{2}=0 \%$} \\
\hline \multicolumn{9}{|c|}{ Test for overall effect: $Z=1.43(P=0.15)$} \\
\hline & & & & & & & $\begin{array}{ll} & 1 \\
0.01 & 0.1\end{array}$ & $\begin{array}{ll}1 & +\end{array}$ \\
\hline \multicolumn{9}{|c|}{ Test for subgroup differences: $\mathrm{Chi}^{2}=0.10, \mathrm{df}=2(\mathrm{P}=0.95), \mathrm{I}^{2}=0 \%$} \\
\hline \multicolumn{9}{|c|}{ Fig. 3 Forest plots of preoperative pancreatitis rates } \\
\hline
\end{tabular}

pancreatitis and cholangitis. Severe cases may also lead to complications such as sepsis and disseminated or diffuse intravascular coagulation (DIC), all of which may result in the loss of surgical intervention. Surgical resection is the only way to cure MBO. Surgery depends not only on the tumor itself but also on jaundice, liver function, the physical condition of the patient, and other complications [12]. Therefore, some patients must be treated with PBD to reduce jaundice in order to make surgery tolerable. Previous treatment for obstructive jaundice caused by MBO often used PTBD for biliary drainage $[17,18]$. In recent studies, surgeons have preferred endoscopic biliary drainage to PTBD, taking into consideration the quality of life for patients and avoiding the spread of tumors and serious complications [19-21]. The operation of ENBD and EBS is relatively simple. At present, there is no randomized controlled clinical study comparing the clinical efficacy of these 2 PBD methods before radical resection of $\mathrm{MBO}$ cancer. Long patency drainage methods are often desired in patients who could not undergo surgery. For the temporary PBD before resecting $\mathrm{MBO}$, the effect of drainage and the effect of PBD on the operation should be considered. In this study, the advantages and disadvantages of 2 kinds of drainage effects and complications were systematically discussed.

Inflammatory reactions including cholangitis and pancreatitis after post-ERCP are unavoidable in endoscopic biliary drainage $[22,23]$. ENBD is an exogenous operation to drain bile and relieve biliary obstruction. It is convenient for biliary cytology and cholangiography [24]. However, long-term indwelling of a nasobiliary duct after ENBD may cause discomfort to laryngeal stimulation and disturbance of water and electrolyte, and there is a risk of the nasobiliary duct breaking or falling off due to the influence of hepatointestinal circulation. EBS, as an internal biliary drainage method, connects the biliary tract and duodenum with a stent without the 


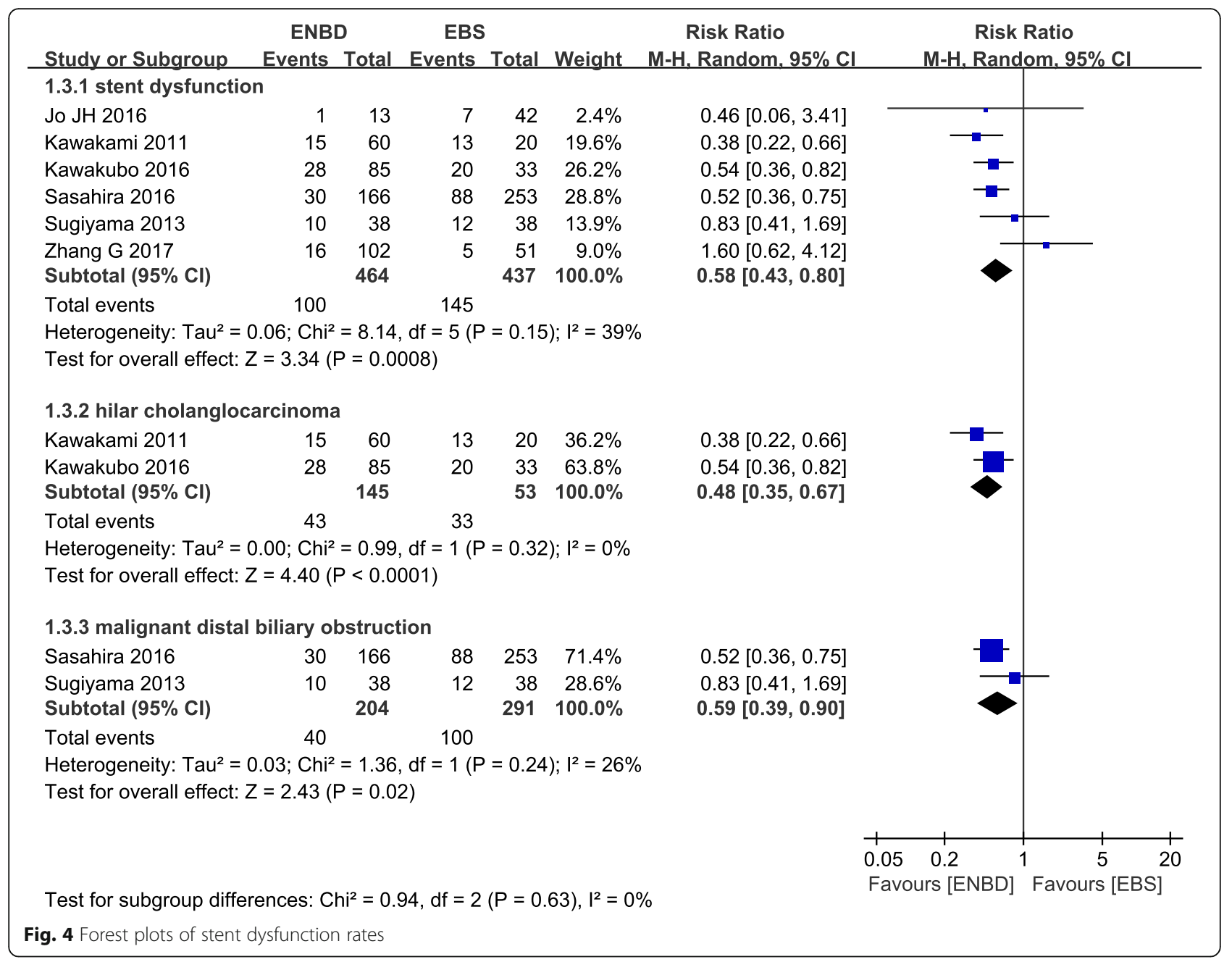

abovementioned adverse effects. When EBS is used for distal malignant obstruction, the stent will obstruct due to the role of intestinal microorganisms, leading to food reflux. This is one of the causes of biliary tract infection and preoperative cholangitis, as well as one of the potential risks of complications of postoperative infection $[8,25]$.

Four studies included in this study had reported that the incidence of preoperative cholangitis in the ENBD group was significantly lower than that in EBS group. After combining the results, both total and hilar cholangiocarnoma subgroup analysis showed a lower preoperative incidence of cholangitis in ENBD, which was consistent with other studies $[26,27]$.

In addition, meta-analysis showed that the incidence of preoperative pancreatitis and stent dysfunction in the EBS group was higher than that in ENBD group, and the causes of the dysfunction were EBS stent occlusion and ENBD stent dislocation. Whether MBO biliary drainage is adequate or not is directly related to the degree of organ damage. Biliary obstruction and cholangitis due to poor biliary drainage will also have a great impact on the survival period and the quality of life of patients. Due to the advantages of rinsing in vitro, ENBD can effectively guarantee the smooth degree of drainage, prolong the survival time, and improve the quality of life for patients. Meta-analysis results provide evidence for this.

Pancreatic fistula, delayed gastric emptying, biliary fistula, and deep abdominal infection are the most common morbidities after pancreaticoduodenectomy (PD). Studies have shown that PBD causes bacterial translocation in the biliary tract, leading to cholangitis associated with this process, which makes the incidence of wound infection significantly higher than that of patients who did not receive PBD treatment before a pancreaticoduodenectomy (PD) $[19,20]$. Fujii et al. also reported that the positive rate of bile or drainage fluid culture in the ERBD group was significantly higher than that in the ENBD group, and that the incidence of an abdominal abscess was significantly higher [8]. Zhang et al. did not find the difference of the overall complications of PD between the ENBD group and the EBS group; there was a significant difference in the incidence of deep abdominal 


\begin{tabular}{|c|c|c|c|c|c|c|c|}
\hline $\begin{array}{l}\text { A } \\
\text { Study or Subgroup }\end{array}$ & $\begin{array}{l}\text { ENBD } \\
\text { Events }\end{array}$ & Total & $\begin{array}{l}\text { EBS } \\
\text { Events }\end{array}$ & Total & Weight & $\begin{array}{c}\text { Risk Ratio } \\
\text { M-H, Fixed, } 95 \% \mathrm{Cl}\end{array}$ & $\begin{array}{c}\text { Risk Ratio } \\
\text { M-H, Fixed, 95\% Cl }\end{array}$ \\
\hline Huang X 2015 & 11 & 18 & 27 & 37 & $16.5 \%$ & $0.84[0.55,1.27]$ & \\
\hline Jo JH 2016 & 2 & 13 & 18 & 42 & $8.0 \%$ & $0.36[0.10,1.35]$ & \\
\hline Kawakami 2011 & 23 & 60 & 13 & 20 & $18.2 \%$ & $0.59[0.37,0.93]$ & \\
\hline Sugiyama 2013 & 13 & 38 & 16 & 38 & $15.0 \%$ & $0.81[0.46,1.45]$ & 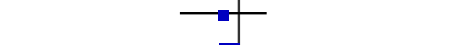 \\
\hline Zhang G 2017 & 60 & 102 & 34 & 51 & $42.4 \%$ & $0.88[0.69,1.14]$ & \\
\hline Total $(95 \% \mathrm{Cl})$ & & 231 & & 188 & $100.0 \%$ & $0.77[0.64,0.93]$ & 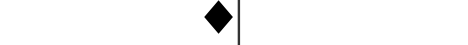 \\
\hline Total events & 109 & & 108 & & & & \\
\hline $\begin{array}{l}\text { Heterogeneity: } \mathrm{Chi}^{2}= \\
\text { Test for overall effect: }\end{array}$ & $\begin{array}{l}.91, \mathrm{df}=4 \\
Z=2.68(P\end{array}$ & $\begin{array}{l}4(P=0 \\
P=0.06\end{array}$ & $\begin{array}{l}0.42) ; 1^{2}=( \\
07)\end{array}$ & $0 \%$ & & & $\begin{array}{llll}0.05 & 0.2 & 1 & 5 \\
\text { Favours [ENBD] } & \text { Favours [EBS] }\end{array}$ \\
\hline $\begin{array}{l}\text { B } \\
\text { Study or Subgroup }\end{array}$ & $\begin{array}{l}\text { ENBD } \\
\text { Events }\end{array}$ & Total & $\begin{array}{l}\text { EBS } \\
\text { Events } \\
\end{array}$ & & Weight & $\begin{array}{l}\text { Risk Ratio } \\
\text { M-H, Fixed, } 95 \% \mathrm{Cl}\end{array}$ & $\begin{array}{c}\text { Risk Ratio } \\
\text { M-H, Fixed, } 95 \% \mathrm{Cl} \\
\end{array}$ \\
\hline Fujii T 2015 & 8 & 50 & 26 & 72 & $38.2 \%$ & $0.44[0.22,0.90]$ & \\
\hline Huang X 2015 & 3 & 18 & 10 & 37 & $11.7 \%$ & $0.62[0.19,1.97]$ & \\
\hline Zhang G 2017 & 34 & 102 & 21 & 51 & $50.1 \%$ & $0.81[0.53,1.24]$ & \\
\hline Total $(95 \% \mathrm{Cl})$ & & 170 & & 160 & $100.0 \%$ & $0.65[0.45,0.92]$ & \\
\hline $\begin{array}{l}\text { Total events } \\
\text { Heterogeneity: } \text { Chi }^{2}= \\
\text { Test for overall effect: }\end{array}$ & $\begin{array}{c}45 \\
17, \mathrm{df}=2 \\
=2.42(P\end{array}$ & $\begin{array}{l}2(P=0 \\
=0.02\end{array}$ & $\begin{array}{l}57 \\
\text { 2) } 34) ;\left.\right|^{2}=\varepsilon\end{array}$ & $8 \%$ & & & \begin{tabular}{lcc|cccc}
1 & 1 & 1 & 1 & 1 & 1 \\
0.1 & 0.2 & 0.5 & 1 & 2 & 5 & 10 \\
Favours & {$[E N B D]$} & Favours & {$[E B S]$}
\end{tabular} \\
\hline
\end{tabular}

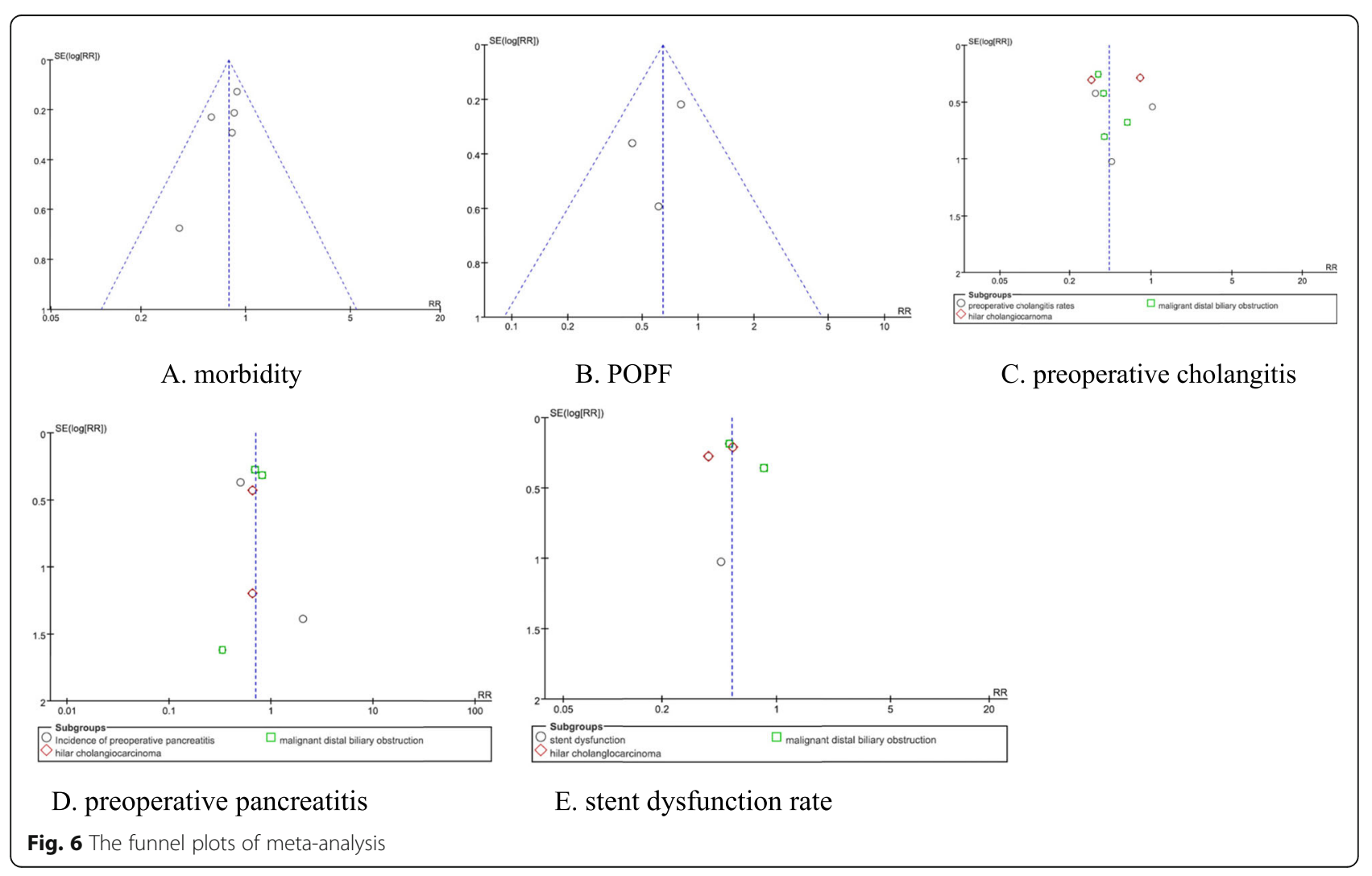


infections but not in wound infections or pulmonary infections [16]. The evidence shows that the infection complications of PD are important factors affecting the treatment of EBD. Therefore, the reduction of morbidity of PD after an operation is an index to evaluate the efficacy of ENBD and EBS. In the enrolled literature, only Kawakami et al. suggested that the morbidity of ENBD was significantly lower than that of EBS [11], while other studies reported that there was no significant difference between the 2 groups. However, the pooled results showed that the incidence of ENBD was significantly lower than that of EBS.

Therefore, preoperative biliary drainage for $\mathrm{MBO}$ patients can give priority to ENBD. When stent dysfunction or intolerance occurs, the nasobiliary duct is replaced by a biliary stent, a so-called bridge PBD. Studies have shown that bridge PBD can shorten the length of the preoperative hospital stay and enables PBD to be carried out for a long time without aggravating the prognosis after PD [28].

\section{Conclusion}

Regardless of the type of $\mathrm{MBO}$, the rates of preoperative cholangitis, preoperative pancreatitis, post-operative pancreatic fistula, stent dysfunction, and morbidity of ENBD patients were lower than those of EBS patients. In clinical practice, the physical condition of each patient and their tolerance should be fully considered. ENBD should be given priority. EBS should be replaced if stent dysfunction or intolerance occurs.

\section{Limitation}

There are several limitations in this article. First, most of the literature is a retrospective study. Although retrospective studies can reflect the application value of the real world, there may be selection bias in these non-randomized controlled studies. Second, since malignant biliary obstruction includes a variety of malignant tumors, although subgroup analysis is performed, its high level of mixed pathology may affect the applicability of this review.

\section{Supplementary information}

Supplementary information accompanies this paper at https://doi.org/10. 1186/s12957-020-01848-1.

Additional file 1: Appendix file 1. the Preferred Reporting Items for Systematic Reviews and Meta-Analyses (PRISMA) 2009 Checklist. Appendix file 2. the Risk of bias in the included retrospective cohort studies (by the Newcastle-Ottawa quality assessment tool). Appendix file $\mathbf{3}$. Meta-Analysis Results of All Available Studies in Measured Outcomes. Appendix file 4. the forest map of the incidence of incidence of preoperative cholangitis. Appendix file 5. the forest map of the incidence of incidence of preoperative pancreatitis. Appendix file 6. the forest map of the incidence of stent dysfunction rate. Appendix file 7. the forest map of the incidence of morbidity. Appendix file 8. the forest map of the incidence of Postoperative Pancreatic Fistula (POPF). Appendix file 9. Assessment of risk of bias. Appendix file 10. PRISMA 2009 flow diagram of literature screening. Appendix file 11. Basic characteristics and quality assessment of enrolled documents

\section{Abbreviations}

PBD : Preoperative biliary drainage; $\mathrm{MBO}$ : Malignant biliary obstruction; ENBD: Endoscopic nasobiliary drainage; EBS: Endoscopic biliary stenting; PTBD: Percutaneous transhepatic biliary drainage; POPF: Postoperative pancreatic fistula

\section{Acknowledgements}

The authors thank all the anonymous reviewers and editors for their helpful suggestions to improve the quality of our paper. There is no one who contributed towards the article who does not meet the criteria for authorship including anyone who provided professional writing services or materials.

Ethical approval was not necessary, as this study was a "Systematic Review and Meta-analysis." There are no individual person's data and presentations of case reports involved in this article.

\section{Authors' contributions}

Wei Zhang: First author, mainly written this document Xu Che: Guide modification and typesetting. All authors read and approved the final version of the manuscript.

\section{Funding}

This research did not receive any specific grant from funding agencies in the public, commercial, or non-for-profit sectors.

\section{Availability of data and materials}

All the data comes from databases. The author has sorted out all the data and attached to the attachment at the end of the article.

\section{Consent for publication}

Consent for publication was not necessary, as this study was a "Systematic Review and Meta-analysis." There are no any individual person's data in any form (including individual details, images, or videos) in this article.

\section{Competing interests}

The authors declare that there are no conflicts of interest regarding the publication of this paper.

Received: 23 December 2019 Accepted: 30 March 2020 Published online: 10 April 2020

\section{References}

1. Bergquist A, von Seth E. Epidemiology of cholangiocarcinoma. Best Pract Res Clin Gastroenterol. 2015 Apr;29(2):221-32.

2. Moole H, Bechtold M, Puli SR. Efficacy of preoperative biliary drainage in malignant obstructive jaundice: a meta-analysis and systematic review. World J Surg Oncol. 2016 Jul 11;14(1):182.

3. Chen P, Li B, Zhu Y, Chen W, Liu X, Li M, Duan X, Yi B, Wang J, Liu C, Luo X, Li $X$, Li J, Liang L, Yin X, Wang $H$, Jiang $X$. Establishment and validation of a prognostic nomogram for patients with resectable perihilar cholangiocarcinoma. Oncotarget. 2016 Jun 14;7(24):37319-30.

4. Yoshida Y, Ajiki T, Ueno K, Shinozaki K, Murakami S, Okazaki T, Matsumoto T, Matsumoto I, Fukumoto T, Usami M, Ku Y. Preoperative bile replacement improves immune function for jaundiced patients treated with external biliary drainage. J Gastrointest Surg. 2014 Dec;18(12):2095-104.

5. El-Hanafy E. Preoperative biliary drainage in hilar cholangiocarcinoma, benefits and risks, single center experience. Hepatogastroenterology. 2010 May-Jun;57(99-100):414-9.

6. Wang $L$, Lin N, Xin F. A systematic review of the comparison of the incidence of seeding metastasis between endoscopic biliary drainage and percutaneous transhepatic biliary drainage for resectable malignant biliary obstruction. World J Surg Oncol. 2019;17(1):116.

7. Hwang S, Song GW, Ha TY, Lee YJ, Kim KH, Ahn CS, Sung KB, Ko GY, Kim MH, Lee SK, Moon DB, Jung DH, Park GC, Lee SG. Reappraisal of percutaneous transhepatic biliary drainage tract recurrence after resection of perihilar bile duct cancer. World J Surg. 2012 Feb;36(2):379-85.

8. Fujii T, Yamada S, Suenaga M, Kanda M, Takami H, Sugimoto H, Nomoto S, Nakao A, Kodera Y. Preoperative internal biliary drainage increases the risk of bile juice infection and pancreatic fistula after pancreatoduodenectomy: a prospective observational study. Pancreas. 2015 Apr;44(3):465-70.. 
9. Huang $X$, Liang $B$, Zhao XQ, Zhang FB, Wang XT, Dong JH. The effects of different preoperative biliary drainage methods on complications following pancreaticoduodenectomy. Medicine (Baltimore). 2015 Apr;94(14):e723.

10. Jo JH, Chung MJ, Han DH, Park JY, Bang S, Park SW, Song SY, Chung JB. Best options for preoperative biliary drainage in patients with klatskin tumors. Surg Endosc. 2017 Jan;31(1):422-9.

11. Kawakami H, Kuwatani M, Onodera M, Haba S, Eto K, Ehira N, Yamato H, Kudo T, Tanaka E, Hirano S, Kondo S, Asaka M. Endoscopic nasobiliary drainage is the most suitable preoperative biliary drainage method in the management of patients with hilar cholangiocarcinoma. J Gastroenterol. 2011 Feb;46(2):242-8.

12. Kawakubo K, Kawakami H, Kuwatani M, Haba S, Kudo T, Taya YA, Kawahata S, Kubota Y, Kubo K, Eto K, Ehira N, Yamato H, Onodera M, Sakamoto N. Lower incidence of complications in endoscopic nasobiliary drainage for hilar cholangiocarcinoma. World J Gastrointest Endosc. 2016 May 10;8(9): $385-90$

13. Nakai Y, Yamamoto R, Matsuyama M, Sakai Y, Takayama Y, Ushio J, Ito Y, Kitamura K, Ryozawa S, Imamura T, Tsuchida K, Hayama J, Itoi T, Kawaguchi Y, Yoshida Y, Sugimori K, Shimura K, Mizuide M, Iwai T, Nishikawa K, Yagioka H, Nagahama M, Toda N, Saito T, Yasuda I, Hirano K, Togawa O, Nakamura K, Maetani I, Sasahira N, Isayama H. Multicenter study of endoscopic preoperative biliary drainage for malignant hilar biliary obstruction: e-pod hilar study. J Gastroenterol Hepatol. 2018 May;33(5):1146-53.

14. Sasahira N, Hamada T, Togawa O, Yamamoto R, Iwai T, Tamada K, Kawaguchi Y, Shimura K, Koike T, Yoshida Y, Sugimori K, Ryozawa S, Kakimoto T, Nishikawa K, Kitamura K, Imamura T, Mizuide M, Toda N, Maetani I, Sakai Y, Itoi T, Nagahama M, Nakai Y, Isayama H. Multicenter study of endoscopic preoperative biliary drainage for malignant distal biliary obstruction. World J Gastroenterol. 2016 Apr 14;22(14):3793-802.

15. Sugiyama H, Tsuyuguchi T, Sakai Y, Nisikawa T, Miyazaki M, Yokosuka O. Preoperative drainage for distal biliary obstruction: endoscopic stenting or nasobiliary drainage? Hepatogastroenterology. 2013 Mar-Apr;60(122):231-4.

16. Zhang GQ, Li Y, Ren YP, Fu NT, Chen HB, Yang JW, Xiao WD. Outcomes of preoperative endoscopic nasobiliary drainage and endoscopic retrograde biliary drainage for malignant distal biliary obstruction prior to pancreaticoduodenectomy. World J Gastroenterol. 2017 Aug 7;23(29): 5386-94.

17. Karnabatidis D, Spiliopoulos S, Katsakiori P, Romanos O, Katsanos K, Siablis D. Percutaneous trans-hepatic bilateral biliary stenting in bismuth IV malignant obstruction. World J Hepatol. 2013 Mar 27;5(3):114-9.

18. Lau WY, Leung KL, Leung TW, Ho S, Chan M, Liew CK, Leung N, Johnson P, Li AK. Obstructive jaundice secondary to hepatocellular carcinoma. Surgical Surg Oncol. 1995;4(6):303-8.

19. Takahashi Y, Nagino M, Nishio H, Ebata T, Igami T, Nimura Y. Percutaneous transhepatic biliary drainage catheter tract recurrence in cholangiocarcinoma. Br J Surg. 2010 Dec;97(12):1860-6.

20. Kawashima H, Itoh A, Ohno E, Itoh Y, Ebata T, Nagino M, Goto H, Hirooka Y. Preoperative endoscopic nasobiliary drainage in 164 consecutive patients with suspected perihilar cholangiocarcinoma. Ann Surg. 2013 Jan;257(1): $121-7$.

21. Barkay O, Mosler P, Schmitt CM, Lehman GA, Frakes JT, Johanson JF, Qaseem T, Howell DA, Sherman S. Effect of endoscopic stenting of malignant bile duct obstruction on quality of life. J Clin Gastroenterol. 2013 Jul;47(6):526-31.

22. Coté GA, Kumar N, Ansstas M, Edmundowicz SA, Jonnalagadda S, Mullady DK, Azar RR. Risk of post-ERCP pancreatitis with placement of selfexpandable metallic stents. Gastrointest Endosc. 2010 Oct;72(4):748-54.

23. Cheng CL, Sherman S, Watkins JL, Barnett J, Freeman M, Geenen J, Ryan M, Parker H, Frakes JT, Fogel EL, Silverman WB, Dua KS, Aliperti G, Yakshe P, Uzer M, Jones W, Goff J, Lazzell-Pannell L, Rashdan A, Temkit M, Lehman GA. Risk factors for post-ERCP pancreatitis: a prospective multicenter study. Am J Gastroenterol. 2006 Jan;101(1):139-47.

24. Yagioka H, Hirano K, Isayama H, Tsujino T, Sasahira N, Nagano R, Hamada T, Miyabayashi K, Ito Y, Mohri D, Kawakubo K, Kogure H, Sasaki T, Tada M, Koike K. Clinical significance of bile cytology via an endoscopic nasobiliary drainage tube for pathological diagnosis of malignant biliary strictures. J Hepatobiliary Pancreat Sci. 2011 Mar; 18(2):211-5.

25. Cortes A, Sauvanet A, Bert F. Effect of bile contamination on immediate outcomes after pancreaticoduodenectomy for tumor. J Am Coll Surg. 2006; 202(1):93-9.
26. Velanovich V, Kheibek T, Khan M. Relationship of postoperative complications from preoperative biliary stents after pancreaticoduodenectomy. A new cohort analysis and meta-analysis of modern studies. JOP. 2009 Jan 8:10(1):24-9.

27. Wang S, Wang X, Li L, Dai H, Han J. Association of preoperative obstructive jaundice with postoperative infectious complications following pancreaticoduodenectomy. Hepatogastroenterology. 2013 Sep;60(126): $1274-9$.

28. Endo Y, Noda H, Watanabe F, Kakizawa N, Fukui T, Kato T, Ichida K, Aizawa $H$, Kasahara N, Rikiyama T. Bridge of preoperative biliary drainage is a useful management for patients undergoing pancreaticoduodenectomy. Pancreatology. 2019 Jul;19(5):775-80.

\section{Publisher's Note}

Springer Nature remains neutral with regard to jurisdictional claims in published maps and institutional affiliations.
Ready to submit your research? Choose BMC and benefit from:

- fast, convenient online submission

- thorough peer review by experienced researchers in your field

- rapid publication on acceptance

- support for research data, including large and complex data types

- gold Open Access which fosters wider collaboration and increased citations

- maximum visibility for your research: over $100 \mathrm{M}$ website views per year

At BMC, research is always in progress.

Learn more biomedcentral.com/submissions 